\title{
An Integrated MCDM Approach to PLM Software Selection
}

\section{Sanja Puzovic, Jasmina Vesic Vasovic, Miroslav Radojicic, Vladan Paunovic}

University of Kragujevac, Faculty of Technical Sciences Cacak, Svetog Save 65, 32000 Cacak, Serbia

E-mail: sanja.puzovic@ftn.kg.ac.rs; jasmina.vesic@ftn.kg.ac.rs; miroslav.radojicic@ftn.kg.ac.rs; vladan.paunovic@ftn.kg.ac.rs

\begin{abstract}
This paper presents the development of a hybrid multi-criteria decision-making (MCDM) approach for Product Lifecycle Management (PLM) software selection, as an essential part of the PLM concept implementation. The approach is based on the hybrid MCDM process that integrates the Fuzzy Analytic Hierarchy Process (FAHP) and the Preference Ranking Organization Method for Enrichment Evaluations (PROMETHEE). The Fuzzy AHP has been applied in order to overcome the problem of the vagueness of decision-makers' judgments in the process of the criteria relative significance assessment, whereas, the PROMETHEE method has been applied in order to evaluate the pieces of software. This paper's findings should indicate the broad possibilities of the proposed model for an objective evaluation of PLM software, on the basis of their total suitability against the global goal according to the established criteria, and capability for efficiently overcoming the problem of data vagueness that decision-makers are facing during the process.
\end{abstract}

\section{Introduction}

The rise of global processes leads to strengthening competition, strengthening of consumer's awareness and increasingly, more complex and stricter regulations that manufacturers have to adhere to. There is a constant increase of product complexity while the lifecycle shortens, also the market fluctuations and economic uncertainty create pressure on prices and expressed need for a quick response to the consumer's growing and interchangeable requirements. All these are the challenges brought by contemporary global flows, which on their part radically change market conditions and competitive relationships, to overcome those challenges requires adoption of the new knowledge and modifying problem 
reaction and solution approach [1]. To face these challenges, manufacturers must adopt and incorporate the concept of products management process into their business flows throughout their lifecycle, from the idea of "end-of-life", i.e. PLM concept. The PLM refers to the strategic approach to creation, management and use of intellectual capital and products related information throughout their lifecycle, from the initial concept to their withdrawal. Addressing in depth the benefits of the PLM concept implementation is a major issue of many research studies [2, 3, 4, 5, 6]. According to Lämmer and Theiss [2] the PLM is considered as the basic concept for satisfying a series of business requirements with respect to the completeness, visibility and high product data transparency, financial requirements related to costs reduction, revenue growth, product related requirements with respect to innovations and its faster market placement, higher quality and a series of regulatory requirements. The PLM can be observed as an integrated information related approach consisting of people, processes and technologies [3], with purpose to create, store and seek data, information and knowledge about the products throughout their lifecycle [2].

The PLM strategy implementation, as a support to higher corporate goals, requires an appropriate software support, which will create a platform for spotting business possibilities, the PLM process standardization, increase in visibility of a product lifecycle phases and cost reduction. It also supports research-development efforts and product introduction to the market. However, this still remains an open issue, given the fact that there is no PLM software that will fully satisfy complex and specific users' requirements. Since the PLM software selection is a complex and challenging problem, therefore the solution lies in MCDM models for the multiaspect assessment of the considered software, and their ranking based upon the overall suitability according to the global goal, also the concepts which will successfully deal with the problem of data vagueness accompanying this process.

\section{Literature Review}

Researching the problem of the software selection, is the field of interest for many authors, from different areas, resulting in various approaches, which are mainly hybrid, based on a combination of several MCDM methods, which makes it easier to handle the complexity of the problem.

Zaidan et al. [7] shows comparative analysis of the results obtained during the software selection for the Open Source of Electronic Medical Records (OS-EMR) by applying the AHP method integrated with different MCDM techniques, such as Weighted Product Method (WPM), Weighted Sum Model (WSM), Simple Additive Weighting (SAW), Hierarchical Additive Weighting (HAW) and Technique for Order of Preference by Similarity to Ideal Solution (TOPSIS). The combination of the AHP and TOPSIS methods is a model frequently used for 
software selection, where the AHP is used in the criteria weight assessment, and TOPSIS for determining the rank of the alternatives. This approach has been used in the selection of the Extract, Transform and Load (ETL) software in the paper [8], whereas in the paper [9], the criteria assessment for the selection of collaborative software was performed by applying the fuzzified AHP method, while the TOPSIS method has been used to evaluate the alternatives. For software selection for the needs of an electronic company, Efe [10] proposes a hybrid multi criteria group decision-making approach, based on the integration of the Fuzzy AHP and Fuzzy TOPSIS. Yazgan et al. [11] attempted to address this issue using the Analytical Network Process (ANP) and the Artificial Neural Network (ANN), the approach implying that, in the creation of an ANP model, the opinions of a group of experts are reduced to the unique values with the help of the geometrical mean technique, after which obtained ANP results are used in creation of an ANN model in order to determine the priority of the considered ERP pieces of software.

Gürbüz et al. [12] propose a framework for ERP software evaluation, which integrates three methods: ANP, Choquet Integral (CI) and Measuring Attractiveness by a Categorical Based Evaluation Technique (MACBETH), where ANP defines the rank of alternatives, whereas the CI and MACBETH do the research in conjunctive or disjunctive criteria behavior. Lee et al. [13] propose AHP method application in solving the problem of the Open Source Customer Relationship Management (OS-CRM) software evaluation. Shukla et al. [14], developed a model for software selection, formed by combining the Stepwise Weight Assessment Ratio Analysis (SWARA) which is used for criteria prioritization and the PROMETHEE method, used for ranking alternatives.

Rouhani and Rouhani [15] have introduced a new approach in the selection of the Information Technology Service Management (ITSM) software, that implies software evaluation on the basis of functional and non-functional criteria by applying the Fuzzy Superiority and Inferiority Ranking (FSIR) method.

\section{A Methodological Framework}

The decision support model for the multi-criteria PLM software selection proposed in the paper represents a hybrid MCDM based approach, formed by integration of the PROMETHEE and the Fuzzy AHP methods. The problem structuring and criteria prioritization processes are realized by applying the Fuzzy AHP method, the results of this phase are further integrated within the process of evaluating alternatives by the PROMETHEE method.

Throughout the utilization of the PROMETHEE method, certain ambiguities related to designing the problem structure and the assessment of the criteria relative importance can be observed, limiting the rationality of decisions made; therefore, with the aim of overcoming these weaknesses, it is necessary to adopt 
certain concepts from the other MCDM methods, and implement them within the PROMETHEE procedure. The first extension of the PROMETHEE method in this paper was performed by adoption of the problem structuring concept according to the AHP methodology, which allows problem solving by decomposing it down into hierarchy of decision-making elements of a different levels, which facilitates understanding of the importance of each element. On the other hand, the PROMETHEE method doesn't offer this structural possibility, which makes gaining an insight into the complexity of the problem more difficult and limits rationality of the final solution.

The PROMETHEE method does not provide clear guidelines to the assessment of criteria importance, either, but it is rather left to the decision-makers' rough estimate, and, as such, is imprecise and unreliable. The criteria used in the process of alternatives evaluation are expressed in different measure units with different requirements of minimization or maximization, they are changeable in time, heterogeneous, and frequently contradictory, as well $[1,16]$, whereas their relative significance is a variable category and depends on a concrete situation, as well as on the decision-maker's subjective perceptions. Besides, the significance attributed to criteria determines to a great extent the final selection, so, pursuant to the importance of this problem issue, it is necessary within the MCDM process, that much more complex approaches to the determination of the criteria relative weight than that offered by the PROMETHEE method should be included.

The criteria relative weights might be assigned in a normalized manner; however, a more suitable manner for their expressing is by using preference relation and linguistic expressions, given the fact that it is closer to the manner of human thinking. So far, several methods have been developed and used for criteria prioritization. In a study [17], the Linear Programming Technique for Multidimensional Analysis of Preference (LINMAP) is exposed, within which the relative weights of criteria are determined by means of the linear programming model. Hafezalkotob and Hafezalkotob [18] present the Fuzzy entropy-weighted MULTIMOORA method, within which the relative weights of criteria are determined on the basis of the entropy concept under the fuzzy environment, whereas in the paper [19] the geometric least square technique for the determination of the values of weight intervals from interval fuzzy preference relations is presented.

One of the most frequently applied principles for criteria prioritization - the Eigenvector Method (EM) - was introduced by Saaty [20], within the AHP method, within this principle the preference relations are described by a multiplied preferences relation, i.e. the pairwise matrix, which further translates into the problem of determining eigenvalues for the purpose of obtaining normalized weighted vectors. Wang and Chin [21] propose a modification of the EM by introducing a new approach, called the Linear Programming Approximation to the EM (LPAEM), which provides quite a consistent matrix of criteria comparison. There are several different prioritization techniques, presented in the literature, 
that are used within the AHP procedure: Least Squares (LS) method [22], the Goal Programming (GP) method [23], the Fuzzy Preference Programming (FPP) method [24], the Linear Programming (LP) method [25], the Weighted Least Square method and Quadratic Programing method [26], the Logarithmic Least Squares (LLS) method [27] and the Geometric Mean (GM) method [28]. Also, herein, special attention is drawn to the approaches, based on describing a preference relationship, by means of the linguistic expressions, mathematically described by fuzzy numbers, which helps overcome the problem of the imprecision of the DM's assessments.

\subsection{The Concept of the Fuzzy AHP Method}

The AHP is an MCDM method developed by Saaty [20], it is frequently applied method in solving complex decision-making problems where it is necessary to include a series of different attributes that are difficult to formalize. Apart from its simplicity, the conventional AHP method shows certain weaknesses, which limit its application in situations when there is any indefiniteness whatsoever in the data about the problem that is being considered, and also, the AHP method is criticized that it doesn't fully reflect a human way of thinking. Most often, authors point at the limitations that are related to the problem of the Eigenvector method, the unbalanced evaluation scale, and pairwise comparison. As the eigenvector solution is based on the description of the problem and an arbitrary order of the factors, this method shows shortcomings with respect to the adjustment of ratio measurements, so it is incapable of retaining the capacity of isomorphism between ratio and difference estimation problems [29].

The conventional AHP method offers an insufficiently precise ranking based on the unbalanced estimation scale because of the neglecting of the uncertainty that may appear when copying the decision-maker's imprecise perceptions onto the numerical estimation scale [30]. The final result in the AHP method is determined by the subjective estimation of the decision-maker while simultaneously the majority of them rely on subjective perceptions, their knowledge or prior experience. Decision-makers, however, are frequently unable to precisely express their preferences due to incomplete information, the complexity and indefiniteness of the decision-making problem, or yet a lack of an appropriate comparison scale. The conventional AHP method could be appropriate solution if the decisionmaker's preferences might be express by means of static crisp values, which is not the case with unreliable and imprecise preferences; expressing them by linguistic descriptions is closer to human way of thinking; however, the uncertainty that can occur when copying imprecise perceptions onto the numerical estimation scale is neglected. This limitation is possible to overcome by using the fuzzy numbers that adequately represent fuzzy linguistic variables, that are broadly applied due to their capability to successful establish a compromise between the descriptive power and computational simplicity [31]. By using fuzzy numbers, it is possible to 
quantitatively describe linguistic variables in an appropriate manner, by which the problem of their sharp classification on Saaty's Scale is successfully overcome.

The fuzzy AHP method was first introduced by Van Laarhoven and Pedrycz [32], who developed the fuzzy logarithmic least squares method. Within this process a system of normal equations for a fuzzy case with several degrees of freedom is obtained by minimizing logarithmic squares method. So far, several Fuzzy AHP models that mainly differ from one another in the manner of the fuzzification of the evaluation scale, (where the fuzzification of the linguistic expressions on Saaty's Scale by means of triangular and trapezoidal fuzzy numbers is the most present), have been developed: the geometrical mean method [33], the synthetic extend analysis method [34], the fuzzy method of the least square [35], the lambda-max method [36], the fuzzy preference programming method [37], the two-stage logarithmic programming method [38], the modification of logarithmic least squares method [39].

The criteria prioritization process within this paper was carried out by using the extent analysis method developed by Chang [34]. This Fuzzy AHP model is based on the fuzzification of imprecise preferences while performing a pairwise comparison by means of triangular fuzzy numbers, which is followed by implementation of the extent analysis method [34] into the process in order to determine relative weights by means of the synthetic extent value. Decisionmakers express their subjective preferences when comparing criteria by means of linguistic expressions, each linguistic expression is assigned a numerical value that is, due to the indefiniteness of expressed preferences, it is given in the form of a triangular fuzzy number adopted from the fuzzified Saaty Scale (Table 1).

Table 1

Fuzzified Saaty Scale

\begin{tabular}{|l|l|l|}
\hline Fuzzy number & Linguistic term & Scale of fuzzy numbers \\
\hline$' 1$ & Equally important & $(1,1,1)$ \\
\hline$' 3$ & Weakly important & $(2,3,4)$ \\
\hline$' 5$ & Essentially important & $(4,5,6)$ \\
\hline$' 7$ & Very strongly important & $(6,7,8)$ \\
\hline$' 9$ & Absolutely important & $(7,8,9)$ \\
\hline$' 2, ' 4, ' 6, ' 8$ & Intermediate values (' $x)$ & $(x-1, x, x+1)$ \\
\hline $1 /$ 'x & Between two adjacent judgments & $(1 / x+1,1 / x, 1 / x-1)$ \\
\hline
\end{tabular}

The fuzzified comparison matrix $M=\left\{M_{g i}^{j}\right\}$ with $n$ goals and $m$ attributes is given in (1). where $M_{g i}^{j}=\left(l_{i j}, m_{i j}, u_{i j}\right)$ is the triangular fuzzy number that stands for a normalized and convex fuzzy set characterized by a closed confidence interval $\left[l_{i j}, u_{i j}\right]$ and the degree of uncertainty $\alpha$ (Figure 1).

$M=\left|\begin{array}{cccc}M_{g 1}^{1} & M_{g 1}^{2} & \ldots & M_{g 1}^{m} \\ M_{g 2}^{1} & M_{g 2}^{2} & \cdots & M_{g 2}^{m} \\ \cdots & \cdots & \ldots & \cdots \\ M_{g n}^{1} & M_{g n}^{2} & \cdots & M_{g n}^{m}\end{array}\right|$ 


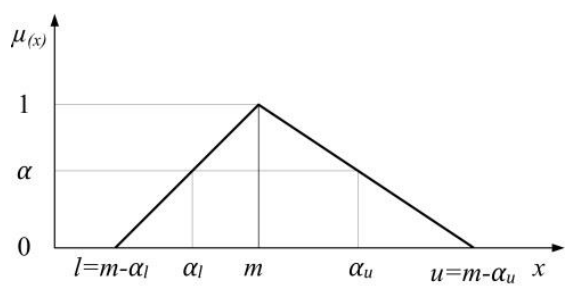

Figure 1

A triangular fuzzy number

Triangular fuzzy numbers are otherwise referred to as "linear" due to their linear membership function, defined as (2).

$\mu_{M}(x)= \begin{cases}\frac{x-l}{m-l}, & x \in[l, m], \\ \frac{x-u}{m-u}, & x \in[m, u], \\ 0, & \text { otherwise }\end{cases}$

The value of a linguistic expression, therefore, belongs to a closed interval $\left[\mathrm{l}_{\mathrm{ij}}, \mathrm{u}_{\mathrm{ij}}\right]$, where the borders of the interval represent the imprecision of the given expression, whereas $\mathrm{m}_{\mathrm{ij}}$ represents the value of the linguistic expression in which the membership function has the highest value $\mathrm{m}_{\mathrm{ij}}=1$.

In the case that the decision-making process includes $\mathrm{n}$ experts, the $\mathrm{n}$ fuzzy comparison matrices are obtained that are possible to aggregate by means of the fuzzy geometrical mean method [33], by which, the aggregated triangular fuzzy number of the assessment of the form $\mathrm{M}_{\mathrm{gi}}^{\mathrm{j}}=\left(\mathrm{l}_{\mathrm{ij}}, \mathrm{m}_{\mathrm{ij}}, \mathrm{u}_{\mathrm{ij}}\right)$ with the triangular membership function whose members are defined by (3), is obtained.

$M_{g i}^{j}=\left(\prod_{k=1}^{n} M_{g i k}^{j}\right)^{\frac{1}{n}}$

where $\mathrm{M}_{\text {gik }}^{\mathrm{j}}$ is the fuzzy relative importance according to the $k^{\text {th }}$ expert's opinion, and $\mathrm{n}$ is the total number of the experts. Based on the obtained aggregated fuzzy comparison matrix $\mathrm{M}_{\mathrm{gi}}^{\mathrm{j}}$ it is possible to compute the fuzzy synthetic extent value $\mathrm{S}_{\mathrm{i}}$ by respecting the algebraic rules for a triangular fuzzy number, by the (4).

$S_{i}=\sum_{j=1}^{m} M_{g i}^{j} \otimes\left[\sum_{i=1}^{n} \sum_{j=1}^{m} M_{g i}^{j}\right]^{-1}$

The $S_{\mathrm{i}}$ could be obtained from the previous relation by the (5).

$S_{i}=\left(l_{i}^{\prime}, m_{i}^{\prime}, u_{i}^{\prime}\right) \otimes\left(\frac{1}{\sum_{i=1}^{n} u_{i}^{\prime}}, \frac{1}{\sum_{i=1}^{n} m_{i}}, \frac{1}{\sum_{i=1}^{n} l_{i}^{\prime}}\right)=\left(\frac{l_{i}^{\prime}}{\sum_{i=1}^{n} u_{i}^{\prime}}, \frac{m_{i}^{\prime}}{\sum_{i=1}^{n} m_{i}^{\prime}}, \frac{u_{i}^{\prime}}{\sum_{i=1}^{n} l_{i}^{\prime}}\right)=\left(l_{i}, m_{i}, u_{i}\right)$

The further procedure requires the determination of the degree of the possibility that: $S_{2}=\left(l_{2}, m_{2}, u_{2}\right) \geq S_{1}=\left(l_{1}, m_{1}, u_{1}\right)$, according to the (6) which is based on the previously obtained fuzzy synthetic extent value: 
$V\left(S_{2} \geq S_{1}\right)=\sup \left[\min \left(\mu_{S_{1}}(x),\left(\mu_{S_{2}}(y)\right)\right]\right.$

This possibility can be expressed through the (7).

$d=\left\{\begin{array}{cc}1, & m_{2} \geq m_{1} \\ 0, & l_{1} \geq u_{2} \\ \frac{l_{1}-u_{2}}{\left(m_{2}-u_{2}\right)-\left(m_{1}-l_{1}\right)} & \text { oterwise }\end{array}\right.$

where $d$ represents the value of the ordinate on the abscissa that corresponds with the highest point of intersection between $S_{2}$ and $S_{1}(8)$, shown in Figure 2.

$V\left(S_{2} \geq S_{1}\right)=\operatorname{hgt}\left(S_{1} \cap S_{2}\right)=\mu_{S_{1}}(d)$

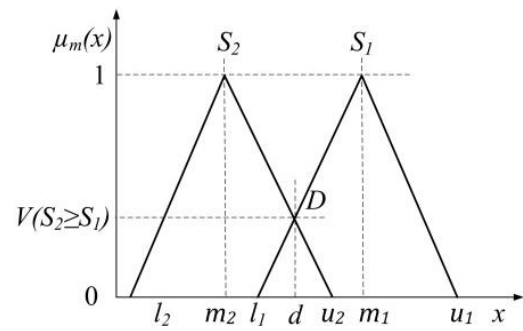

Figure 2

The intersection between $S_{1}$ and $S_{2}$ and their degree of possibility [34]

By finding the preference of $S_{i}$ and $S_{k},(k=1,2, \ldots, n$, where $\mathrm{n}$ is the number of the criteria) the degree of a possibility of obtaining a convex fuzzy number can be calculated by (9).

$V\left(S \geq S_{1}, S_{2}, \ldots, S_{n}\right)=\left[V\left(S \geq S_{1}\right)\right.$ and $V\left(S \geq S_{2}\right)$ and $\left.\ldots V\left(S \geq S_{n}\right)\right]=$ $\min V\left(S \geq S_{i}\right)(i=1,2, \ldots, n)$

Should $d^{\prime}\left(A_{i}\right)=\min V\left(S_{i} \geq S_{k}\right), \quad(k=1,2,3, \ldots, n ; k \neq i)$, then the obtained weight vector has the form as (10):

$w^{\prime}=\left(d^{\prime}\left(A_{1}\right), d^{\prime}\left(A_{2}\right), \ldots, d^{\prime}\left(A_{n}\right)\right)$

By the normalization of the obtained weight vectors the weight of each individual criterion (11) is obtained in the form of a non-fuzzy number.

$w=\left(d\left(A_{1}\right), d\left(A_{2}\right), \ldots, d\left(A_{n}\right)\right)$

\subsection{The Concept of the PROMETHEE Method}

The PROMETHEE method [40] belongs to the MCDM group of methods, and serves to rank the considered alternatives assessed in a multi-criteria system. This method enables the aggregation of the qualitative and quantitative criteria of different importance. So far, several approaches to MCDM-problem solving by 
applying the PROMETHEE method have been developed: PROMETHEE I - for partial ranking; PROMETHEE II, i.e. the "net flow" method, which enables a complete order of all alternatives [40]; the PROMETHEE GAIA descriptive approach to the analysis of the results obtained [41]; PROMETHEE III, for the ranking based on intervals; PROMETHE IV for the multi-criteria analysis of an uninterrupted set of alternatives; PROMETHEE V, for optimization with segmentation limitations [42]; PROMETHEE VI, supportive of the manner which humans think in [43]; the PPROMETHEE CLUSTER, developed for normal classification [44], then Fuzzy PROMETHEE, based on the fuzzy outranking relation to overcome the problem of the indefiniteness, uncertainty and imprecision of data in decision-making [45], and the Modified PROMETHEE, based on the universal preference function [16].

The PROMETHEE procedure consists of the two steps: Construction of an outranking relation by means of the preference index and exploitation of the obtained relations for the purpose of solving the problem.

Let to define the MCDM problem as (12).

$\operatorname{Max}\left(f_{1}(a), f_{2}(a), \ldots, f_{n}(a)\right) \mid a \in A$

where A represents the final set of the alternatives subjected to the ranking, according to the defined criteria for the evaluation - $\mathrm{f}$. For each alternative a from within set $A, f_{i}(a)$ represents the related value as per criterion $f_{i}$. The results of the comparison of the alternatives $a$ and $b(a, b \in A)$ can be expressed in the form of the preference function (13).

$P(a, b)=P(f(a)-f(b))=P(x)$

The preference function $P(a, b)$ has the characteristics: $0 \leq P(a, b) \leq 1$, $P(a, b) \neq P(b, a)$, expresses the intensity of the preference of the alternative $a$ in comparison with the alternative $b$ and can be interpreted as: $P(a, b)=0$ (indifference $-f(a)=f(b)$ ); $P(a, b) \sim 0$ (weak preference - $f(a)>f(b)$ ); $P(a, b) \sim 1$ (strong preference - $f(a)>>f(b)) ; P(a, b)=1$ (strict preference $f(a)>>>f(b))$. The preference function $\mathrm{P}(\mathrm{a}, \mathrm{b})$ is the non-falling function that acquires the zero value for the negative value $f(a)-f(b)$, and can graphically be interpreted as in Figure 3.

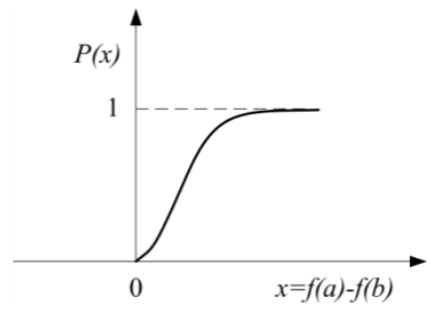

Figure 3

The general preference function 
For each of the criteria, the type of the preference function is determined pursuant to the specificity of the criterion, as well as the related parameters. Brans and Vincke [40] propose six types of the general preference functions that enable the expression of a preference in the majority of real problems.

What follows is the calculation of the preference index according to the (14) that represents the total intensity of the preference of the alternative $a$ over the alternative $b$, according to all of the acknowledged criteria.

$I P(a, b)=\frac{1}{\sum_{i=1}^{n} w_{i}} \sum_{i=1}^{n} P_{i}(a, b) w_{i}$

where $w_{i}$ is the relative weight of the $i^{t h}$ criterion with the characteristics: $w_{i} \in$ $[0,1]$ and $\sum w_{i}=1$.

On the basis of the preference index, it is possible to determine the value of the leaving (15) and the entering (16) flows, and on the basis of these values a partial comparison of alternatives is performed (PROMETHEE I).

$\emptyset^{+}\left(a_{i}\right)=\sum_{x \in A} I P(a, x)$

$\emptyset^{-}\left(a_{i}\right)=\sum_{x \in A} I P(x, a)$

A complete order of the alternatives (PROMETHEE II) requires the balancing of the entering and the leaving flows, i.e. the consideration of the net flow (17).

$\emptyset\left(a_{i}\right)=\emptyset^{+}\left(a_{i}\right)-\emptyset^{-}\left(a_{i}\right)$

\section{Problem Definition and Modeling}

The decision-making problem considered in this paper relates to the selection of the adequate PLM software, it has been expressed a request for software that provides the necessary modules and functions for service provision and the integration of the basic PLM processes and the creation of the centralized data source for all the participants in the value chain, apart from which such software should satisfy certain requirements with respect to the technical characteristics. The software should also be learnable and efficient, with understandable models and concepts, adaptive to the specificities of production and business doing within different industries, as well as of acceptable costs.

The proposed model for PLM software selection is based on a hybrid multicriteria approach. The basis of this process consists of the designing a MCDM base, which implies the generation of potential alternatives and the development of the system of criteria for their evaluation. Then, criteria prioritization, a multicriteria evaluation of the alternatives, their ranking, the selection of the optimal solution and the results analysis by sensitivity analysis which facilitates the final 
selection for the decision makers. The proposed model enables linking of all data and relations into a rational whole, which enables the analysis and understanding the problem with all of its logical connections, complexity, specificities and possible uncertainties, and then, the realization of a rational decision.

\section{The Application of the Proposed Model for PLM Software Selection}

The decision team formed of five experts from the industries such as: high-tech electronics, retail, medical devices, industrial manufacturing and automotive, has been involved through the entire process of PLM software selection. Those experts are with work experiences of 5-12 years and academic, engineering and IT background, also they are with experience in implementing the PML concept.

Step 1: The Construction of the Problem Hierarchical Structure - The expert team generated 12 alternatives - PLM pieces of software with required characteristics (Figure 4). The measuring and understanding of the total suitability of those alternatives against the global goal requires the recognition of different evaluation aspects, i.e. the translation of the general decision-making goals into the criteria on the basis of which alternatives will be evaluate, thus forming the criteria base that serves as the framework for the assessment of the alternatives.

Table 2

The criteria used for software MCDM selection

\begin{tabular}{|l|l|l|l|}
\hline Criterion & Paper & Criterion & Paper \\
\hline Usability & {$[7,8,13,46,47,48]$} & Installation factors & {$[7,50]$} \\
\hline Functionality & {$[7,8,13,48,49,50,51,52]$} & Perenniality & {$[9]$} \\
\hline Technical specifications & {$[10,53]$} & Implementability & {$[49]$} \\
\hline User support and service & {$[7,50,52]$} & Learnability & {$[46]$} \\
\hline Cost & {$[8,10,13,47,49,50,51,52$,} & Technology advance & {$[49,51,52]$} \\
\hline 53$]$ & {$[8,10,13,47,49,51,52]$} & Weight of experts & {$[9]$} \\
\hline Vendors factors & {$[7,9,47]$} & Machine-human interface & {$[9]$} \\
\hline Security & {$[13,49,51]$} & Technical architecture & {$[13]$} \\
\hline Flexibility & {$[8,13,47,48,50,51]$} & Portability & {$[47,48]$} \\
\hline Reliability & {$[7]$} & Strategy-fit & {$[49]$} \\
\hline Developer support & {$[46]$} & Operability & {$[46]$} \\
\hline Understandability & {$[50,51,53]$} & System overhead & {$[53]$} \\
\hline Ease of use & {$[7,13,50,52,53]$} & Attractiveness & {$[46]$} \\
\hline Customizability & {$[47,48]$} & Maintainability & {$[48,53]$} \\
\hline Efficiency & & \\
\hline
\end{tabular}

In Table 2, the list of the criteria for the selection of software of different purpose, frequently used in the literature, is presented. As we perceive, there is no universality in criteria selection, but they depend on the type and purpose of software. Although the most frequently used are the criteria that consider functionality, usability and efficiency as the key aspects of software quality, the 
majority of authors resort to expanding the base of the criteria for evaluation, including also the other aspects, such as technical specifications, flexibility, user support and service, ease of use, vendor factors... On the basis of this research, and the experts' and the PLM-software users' experience and assessments, a system of the seven basic criteria for the alternatives evaluation was identified, each of those criteria is explained in several sub-factors, which leads to a more rational evaluation (Figure 4). The selected criteria represent the main dimensions PLM software quality, and by their integration into the selection process all the aspects of the considered problem significant for finding the optimal solution are included.

As the result of the problem structuring carried out in compliance with the AHP methodology, the hierarchical structure of the problem was created (Figure 4).

\begin{tabular}{|c|c|c|c|c|c|c|c|c|c|c|c|c|c|c|}
\hline \multirow[t]{2}{*}{ Goal } & & \multicolumn{5}{|c|}{$\begin{array}{c}\text { Selection of the Most Suitable PLM } \\
\text { Software }\end{array}$} & LM & & & \\
\hline & & & & & & 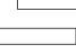 & & & 1 & & 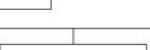 & & & \\
\hline \multirow[t]{2}{*}{ Criteria } & \multicolumn{2}{|c|}{ Functionality } & \multicolumn{3}{|c|}{$\begin{array}{l}\text { Technical } \\
\text { Features } \\
\end{array}$} & \multicolumn{2}{|c|}{ Cost } & \multicolumn{3}{|c|}{ Users Support } & Ease for Use & \multicolumn{2}{|c|}{\begin{tabular}{|c|} 
Industries \\
Covered
\end{tabular}} & Efficiency \\
\hline & & & \multicolumn{2}{|c|}{$\begin{array}{l}\text { Interface } \\
\text { Software } \\
\text { Reliability } \\
\text { Platform } \\
\text { Independency }\end{array}$} & \multicolumn{4}{|c|}{\begin{tabular}{|l|} 
Purchasing cost \\
Cost for upgrading \\
Implementation \\
and \\
training cost \\
Hardware cost
\end{tabular}} & \multicolumn{2}{|c|}{\begin{tabular}{|l||} 
Training rograms \\
Consulting \\
Guides for using \\
Installation guides \\
Website \\
Forums for users \\
\end{tabular}} & \begin{tabular}{|l|} 
Learnability \\
Clarity of \\
model and \\
concepts \\
Error tolerant \\
\end{tabular} & & & \\
\hline \multicolumn{3}{|c|}{ Alternatives } & 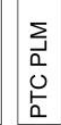 & $\begin{array}{l}\sum \\
0 \\
0 \\
\frac{0}{5} \\
0 \\
\end{array}$ & 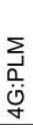 & 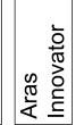 & $\begin{array}{l}0 \\
0 \\
0 \\
0 \\
\infty\end{array}$ & $\begin{array}{l}\sum_{j} \\
0 \\
\stackrel{0}{ \pm} \\
\underline{=}\end{array}$ & 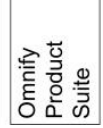 & 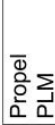 & 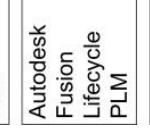 & \begin{tabular}{|l|}
$\sum_{1}$ \\
0 \\
0 \\
0 \\
0 \\
0
\end{tabular} & 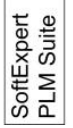 & \\
\hline
\end{tabular}

Figure 4

The hierarchical structure of the PLM software selection problem

In the context of PLM software, criterion Functionality considers whether the software provides the necessary functions, as well as the modules for providing integration of the basic PLM processes and offering a centralized data source for all participants in the value chain, such as: Bill of Material Analysis, Cost Tracking, Document Management, Product Data Management, Supplier Management, Product Analysis and other. Industries covered criterion relates to the level of the flexibility of the software, i.e. the extent to which the software is capable of responding to the specific production challenges faced by manufacturers from a wide range of industries.

Step 2: The Assignation of the Criteria Relative Weights - According to the subjective preferences of the group of five experts, involved in the decision making process, about the importance of the established criteria, the individual fuzzy pairwise comparison matrices were formed by using the linguistic variables that were subsequently translated into the appropriate fuzzy numbers according to the fuzzified scale (Table 1). By calculating the fuzzy geometrical mean of the experts' individual matrices according to (3), the aggregated fuzzy pairwise 
comparisons matrix (Table 3) is formed. The consistency of both all individual matrices and the aggregated matrix is less than 0.1 , which is indicative of the consistency of the criteria evaluation and ensures a required level of the quality of the decision, so the procedure may continue.

Table 3

The fuzzy aggregated pairwise comparison matrix

\begin{tabular}{|l|l|l|l|l|l|l|l|}
\hline & $\mathrm{C}_{1}$ & $\mathrm{C}_{2}$ & $\mathrm{C}_{3}$ & $\mathrm{C}_{4}$ & $\mathrm{C}_{5}$ & $\mathrm{C}_{6}$ & \multicolumn{1}{c|}{$\mathrm{C}_{7}$} \\
\hline $\mathrm{C}_{1}$ & $(1,1,1)$ & $(1.74,2.77,3.78)$ & $(0.74,1.25,2.05)$ & $(0.52,0.76,1.25)$ & $(2.61,3.65,4.68)$ & $(2.22,3.29,4.32)$ & $(1.64,2.7,3.73)$ \\
\cline { 2 - 8 } $\mathrm{C}_{2}$ & $(0.26,0.36,0.57)$ & $(1,1,1)$ & $(0.61,1.06,1.68)$ & $(0.37,0.5,0.74)$ & $(1.4,1.97,2.55)$ & $(0.96,1.55,2.17)$ & $(0.94,1.4,2.06)$ \\
$\mathrm{C}_{3}$ & $(0.49,0.8,1.35)$ & $(0.59,0.94,1.64)$ & $(1,1,1)$ & $(0.38,0.58,0.82)$ & $(1.06,1.78,2.7)$ & $(0.92,1.64,2.55)$ & $(0.87,1.52,2.22)$ \\
\hline $\mathrm{C}_{4}$ & $(0.8,1.32,1.93)$ & $(1.35,2,2.72)$ & $(1.22,1.72,2.61)$ & $(1,1,1)$ & $(1.64,2.7,3.73)$ & $(1.32,2.35,3.37)$ & $(1.64,2.7,3.73)$ \\
\cline { 3 - 8 } $\mathrm{C}_{5}$ & $(0.21,0.27,0.38)$ & $(0.39,0.51,0.72)$ & $(0.37,0.56,0.94)$ & $(0.27,0.37,0.61)$ & $(1,1,1)$ & $(0.47,0.66,1.11)$ & $(0.43,0.61,1)$ \\
\hline $\mathrm{C}_{6}$ & $(0.23,0.3,0.45)$ & $(0.46,0.64,1,05)$ & $(0.39,0.61,1.08)$ & $(0.3,0.43,0.76)$ & $(0.9,1.52,2.14)$ & $(1,1,1)$ & $(1,1.74,2.41)$ \\
$\mathrm{C}_{7}$ & $(0.27,0.37,0.61)$ & $(0.48,0.72,1.06)$ & $(0.45,0.66,1.15)$ & $(0.27,0.37,0.61)$ & $(1,1.64,2.35)$ & $(0.42,0.57,1)$ & $(1,1,1)$ \\
\hline
\end{tabular}

On the basis of the aggregated fuzzy pairwise comparisons matrix the fuzzy synthetic extent values for each of the criteria $\left(S_{i}\right)$ are computed according to (5), the value $S_{i}$ for the remaining criteria is accounted for in Table 4.

Table 4

The fuzzy synthetic extent values, the possibilities matrix and the weight vectors

\begin{tabular}{|c|c|c|c|c|c|c|c|c|c|c|}
\hline \multirow{2}{*}{ Criterion } & \multirow{2}{*}{$\mathrm{S}_{\mathrm{i}}$} & \multicolumn{7}{|c|}{ The possibilities matrix } & \multirow{2}{*}{$\mathrm{w}_{\mathrm{i}}^{\prime}$} & \multirow[b]{2}{*}{$\mathrm{w}_{\mathrm{i}}$} \\
\hline & & $\overline{\mathrm{C}_{1}}$ & $\mathrm{C}_{2}$ & $\mathrm{C}_{3}$ & $\mathrm{C}_{4}$ & $\mathrm{C}_{5}$ & $\mathrm{C}_{6}$ & $\mathrm{C}_{7}$ & & \\
\hline \begin{tabular}{|l|l|}
$\mathrm{C}_{1}$ & Functionality \\
\end{tabular} & $(0.12,0.25,0.5)$ & - & 1 & 1 & 1 & 1 & 1 & 1 & 1 & 0.265 \\
\hline $\mathrm{C}_{2}$ Technical Features & $(0.06,0.13,0.26)$ & 0.523 & - & 0.966 & 0.612 & 1 & 1 & 1 & 0.5234 & 0.138 \\
\hline \begin{tabular}{l|l}
$\mathrm{C}_{3}$ & Efficiency
\end{tabular} & $(0.06,0.14,0.3)$ & 0.596 & 1 & - & 0.677 & 1 & 1 & 1 & 0.5956 & 0.158 \\
\hline $\mathrm{C}_{4}$ Cost & $(0.11,0.23,0.46)$ & 0.927 & 1 & 1 & - & 1 & 1 & 1 & 0.9268 & 0.245 \\
\hline \begin{tabular}{|l|l}
$\mathrm{C}_{5}$ & Users Support
\end{tabular} & $(0.04,0.07,0.14)$ & 0.078 & 0.537 & 0.519 & 0.171 & - & 0.704 & 0.807 & 0.0776 & 0.021 \\
\hline \begin{tabular}{l|l}
$\mathrm{C}_{6}$ & Industries Covered
\end{tabular} & $(0.05,0.1,0.21)$ & 0.377 & 0.849 & 0.819 & 0.466 & 1 & - & 1 & 0.3765 & 0.1 \\
\hline \begin{tabular}{|l|l}
$\mathrm{C}_{7}$ & Ease for Use \\
\end{tabular} & $(0.05,0.09,0.19)$ & 0.28 & 0.747 & 0.721 & 0.370 & 1 & 0.902 & - & 0.2797 & 0.074 \\
\hline
\end{tabular}

The calculated fuzzy synthetic extent values represent the preference of a certain criterion over other criteria, whereas the possibility of the determined superiority of each individual criterion over other criteria, individually, $V\left(S_{i} \geq S_{k}\right)$ ( $k=$ $1,2,3, \ldots, n ; k \neq i)$, can be determined by means of (7). The obtained values are shown in the possibilities matrix, shown in Table 4.

By minimizing the calculated possibilities, criterion weight vector $w_{i}$ ' is obtained (according to (10)), by whose normalization the final weights of each individual criterion are obtained in the form of the non-fuzzy number $w$ (11). The normalization is possible to perform by means of (18). The criteria weights vectors, as well as their normalized values, are presented in Table 4.

$w=\frac{w_{i}^{\prime}}{\sum_{i=1}^{n} w_{i}^{\prime}}$

The obtained results are indicative of the fact that the Functionality criterion has priority over the other criteria, with the weight coefficient of 0.265 , so it will have 
the greatest influence on the final decision. The Cost criterion with the weight of 0.245 will also have a significant influence on the choice. According to the assessments made by the experts involved in the decision-making process, the criteria with the least influence on the software selection are: Industries Covered, Ease for Use and Users Support.

Step 3: The Evaluation of the Alternatives - The ranking of the considered PLM pieces of software was performed by applying the PROMETHEE method. The basis of this procedure consists of the designing of the MCDM decision-making base (Table 5). Besides, for each criterion a type of the preference function that reflects the specificities of the given criterion in the most appropriate way was selected, after which the related parameters, as well as the requirements for extremization were determined (Table 5). The results obtained in the previous procedure of the criteria evaluation by means of the Fuzzy AHP method were used for the relative weights of the criteria.

Table 5

MCDM base

\begin{tabular}{|l|l|l|l|l|l|l|l|}
\hline Criterion & $\mathrm{C}_{1}$ & $\mathrm{C}_{2}$ & $\mathrm{C}_{3}$ & \multicolumn{1}{l}{$\mathrm{C}_{4}$} & $\mathrm{C}_{5}$ & $\mathrm{C}_{6}$ & $\mathrm{C}_{7}$ \\
\hline \multirow{3}{*}{$\begin{array}{l}\text { Generalized Criteria Type } \\
p\end{array}$} & $\mathrm{III}$ & $\mathrm{VI}$ & $\mathrm{III}$ & $\mathrm{V}$ & $\mathrm{IV}$ & $\mathrm{V}$ & $\mathrm{VI}$ \\
\cline { 2 - 9 }$q$ & 0.2 & - & 2.6 & 1.17 & 1 & 1.2 & - \\
\cline { 2 - 9 } $\begin{array}{l}\sigma \\
\text { Request } \\
\text { Criteria Relative Weight }\end{array}$ & - & & - & 7.33 & 2.5 & 3 & - \\
\cline { 2 - 9 } & - & 0.49 & - & - & - & - & 0,76 \\
\cline { 2 - 9 } & $\mathrm{Max}$ & $\mathrm{Max}$ & $\mathrm{Max}$ & $\mathrm{Min}$ & $\mathrm{Max}$ & $\mathrm{Max}$ & $\mathrm{Max}$ \\
\cline { 2 - 9 } & 0.265 & 0.138 & 0.158 & 0.245 & 0.021 & 0.1 & 0.074 \\
\hline
\end{tabular}

For the considered MDCM problem the evaluation matrix (Table 6) was constructed, which compliantly with the defined hierarchical structure of the problem (Figure 4) encompasses the 12 alternatives assessed in the system of 7 criteria. The evaluation matrix was constructed on the bases of the impressions that the experts, involved in the decision making process, have acquired during testing of the considered PLM pieces of software, also on the bases of the data about the software performance provided by the producers.

Table 6

The evaluation matrix

\begin{tabular}{|c|c|c|c|c|c|c|c|c|c|c|c|c|}
\hline Criteria & 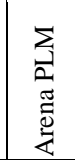 & $\begin{array}{l}\sum_{1} \\
0 \\
0 \\
\vdots\end{array}$ & $\begin{array}{l}\sum_{0} \\
\frac{0}{00} \\
\frac{0}{4}\end{array}$ & $\sum_{\substack{3 \\
\dot{g}}}$ & 总 & 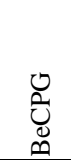 & 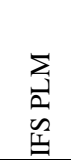 & 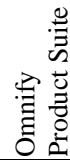 & $\begin{array}{l}\sum_{1} \\
\bar{D} \\
\overline{0} \\
0 \\
0\end{array}$ & 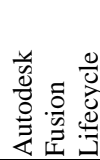 & 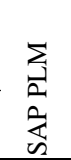 & 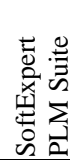 \\
\hline Functionality & 0.579 & 0.526 & 0.632 & 0.316 & 0.526 & 0.579 & 0.421 & 0.632 & 0.474 & 0.368 & 0.684 & 0.526 \\
\hline Technical Features & 3.3 & 3.025 & 4.4 & 4.2 & 3.95 & 3.2 & 3.975 & 3.925 & 4.275 & 3.925 & 4.75 & 4.2 \\
\hline Efficiency & 7.02 & 6.2 & 8.62 & 7.6 & 4.98 & 5.12 & 5.24 & 8.24 & 7.82 & 8.21 & 8.96 & 7.12 \\
\hline Cost & 2.97 & 6 & 10 & 1.67 & 2.23 & 1.5 & 5.67 & 6.67 & 4 & 5 & 10 & 2.8 \\
\hline Users Support & 8.23 & 7.27 & 10 & 6.72 & 6.19 & 8.77 & 9.62 & 7.84 & 8.96 & 6.95 & 9.33 & 7.56 \\
\hline Industries Covered & 2.258 & 1.935 & 2.258 & 0.968 & 4.839 & 1.290 & 3.226 & 1.29 & 1.935 & 4.194 & 4.516 & 3.871 \\
\hline Ease for Use & 8.18 & 7.3 & 7.77 & 8.3 & 6.7 & 8.1 & 6.45 & 8.68 & 7.77 & 7.89 & 7.17 & 9.2 \\
\hline
\end{tabular}


It should be mentioned that, in the evaluation of the alternatives according to the Cost criterion, the costs of the using, implementation, upgrading and training for the software packages that only include some of the available modules which the user had expressed the need for are taken into consideration. Simultaneously, all of the considered software packages are of a roughly equivalent content when the modules included in them are concerned.

For each pair of the compared alternatives, the preference function $P(a, b)$ was determined, according to (13), then the index of the preference $I P(a, b)$ according to (14) that enables the construction of the outranking relation.

Step 4: The ranking of the alternatives - The alternatives rank is determined on the basis of the values of the entering, leaving and net flows (Table 7) calculated according to (15-17).

Table 7

The values of the positive, negative and net flows

\begin{tabular}{|c|c|c|c|c|c|}
\hline \multicolumn{2}{|c|}{ Alternatives } & $\emptyset^{+}\left(a_{i}\right)$ & $\emptyset^{-}\left(a_{i}\right)$ & $\emptyset\left(a_{i}\right)$ & Rang \\
\hline$a_{1}$ & Arena PLM & 0.228 & 0.179 & 0.049 & 5 \\
\hline$a_{2}$ & PTC PLM & 0.102 & 0.353 & -0.251 & 11 \\
\hline$a_{3}$ & Agile PLM & 0.310 & 0.213 & 0.097 & 4 \\
\hline$a_{4}$ & 4G:PLM & 0.214 & 0.309 & -0.095 & 10 \\
\hline$a_{5}$ & Aras Innovator & 0.231 & 0.254 & -0.023 & 7 \\
\hline$a_{6}$ & $\mathrm{BeCPG}$ & 0.221 & 0.277 & -0.056 & 8 \\
\hline$a_{7}$ & IFS PLM & 0.095 & 0.379 & -0.284 & 12 \\
\hline$a_{8}$ & Omnify Product Suite & 0.295 & 0.143 & 0.152 & 3 \\
\hline$a_{9}$ & Propel PLM & 0.210 & 0.174 & 0.036 & 6 \\
\hline$a_{10}$ & Autodesk Fusion Lifecycle & 0.195 & 0.266 & -0.071 & 9 \\
\hline$a_{11}$ & SAP PLM & 0.449 & 0.203 & 0.246 & 1 \\
\hline$a_{12}$ & SoftExpert PLM Suite & 0.303 & 0.106 & 0.198 & 2 \\
\hline
\end{tabular}

The obtained alternative rank (Table 7) based on the preference index indicates that to the greatest extent the SAP PLM software satisfies the established requirements, this alternative has the greatest value of the net flow of 0.246. Somewhat worse ranked alternatives are the pieces of software SoftExpert PLM Suite and Omnify Product Suite with the values of the net flow being 0.198 and 0.152 , respectively. The obtained rank of the considered PLM pieces of software, provides a significant help in making a decision of the PLM software selection.

Step 5: The results analysis - Figure 5 presents the Geometrical Analysis for Interactive Aid (GAIA) plane for the PLM software selection problem. The GAIA plane represents a descriptive approach to the results analysis, understanding the specificities of a problem, the identification of a synergy or conflicts between criteria; it enables the highlighting of the alternatives clusters and the alternatives with exceptional preferences. The quality of the visual display is $80.9 \%$, which indicates that very few information got lost by the results projection. The GAIA plane is indicative of the fact that, between the criteria of Functionality, Users support i Industries covered, there is a synergy; the other group of close criteria consists of Efficiency and Technical features, whereas the criteria Cost and Ease 
for use are conflicting against the other criteria. The pieces of software SAP PLM, AGILE PLM and Omnify Product Suite demonstrate the best features with respect to the functionality and user support, but are of weaker characteristics with respect to the costs and the ease of use in comparison with the other pieces of software.

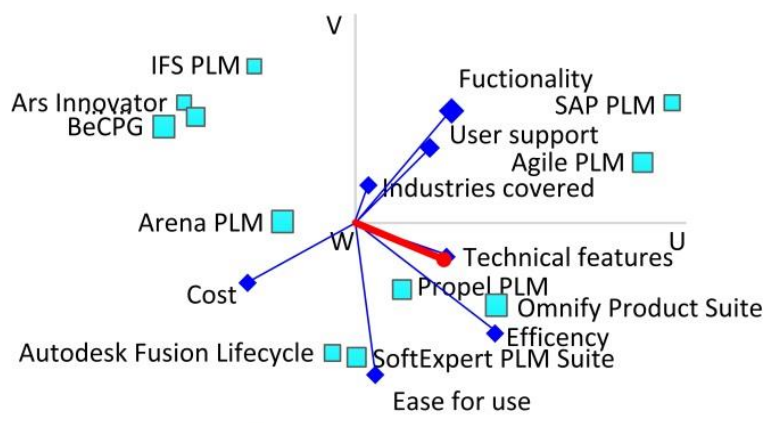

4G:PLM

Figure 5

The GAIA plane for PLM software selection

\section{Conclusion}

The theoretical and practical applications of this work are indicative of the conveniences of the proposed model for PLM software selection. The model is formed by combining two techniques: Fuzzy AHP and PROMETHEE, which are integrated within one MCDM approach, by their inter-complementarity, the weaknesses that they show, which can represent a significant limitation in finding rational solutions, have been overcome. The Fuzzy AHP method enables for obtaining more consistent and more precise criteria weights, in comparison with those determined on the basis of the DM's intuition, which is the case, with the PROMETHEE method. Also, the incorporation of fuzzy set theory into the criteria prioritization process, makes it easier to handle the ambiguities that this process embodies. On the other hand, the PROMETHEE method enriches the proposed approach, by assigning appropriate preference functions to each one of the criteria, in which manner, it reflects their specificity and enables the rational ranking of the considered PLM pieces of software.

The proposed model reduces subjective outcomes and generates much more rational solutions, based on the reliable assessment of criteria weights, problem structuring and overcoming the problems and inconsistencies of human thinking. It offers a multi-aspect evaluation of the considered alternatives and the provision of adequate support to group decision-making and finally, visual analysis of the results obtained. Apart from the PLM software selection, this model is also applicable in solving other real problems that may include various conflicting criteria, in the fuzzy environment. 


\section{References}

[1] J. Vesić Vasović, M. Radojičić, M. M. Klarin, V. K. Spasojević Brkić: Multi-Criteria Approach to Optimization of Enterprise Production Programme, Proceedings of the Institution of Mechanical Engineers, Part B: Journal of Engineering Manufacture, Vol. 225, No. 10, 2011, pp. 1951 1963

[2] L. Lämmer, M. Theiss: Product Lifecycle Management, In Concurrent Engineering in the $21^{\text {st }}$ Century, Springer International, 2015, pp. 455-490

[3] H. Gmelin, S. Seuring: Achieving Sustainable New Product Development by Integrating Product Life-Cycle Management Capabilities, International Journal of Production Economics, Vol. 154, 2014, pp. 166-177

[4] P. S. G. D. Oliveira, D. D. Silva, L. F. D Silva, M. D. S. Lopes, A. Helleno: Factors that Influence Product Life Cycle Management to Develop Greener Products in the Mechanical Industry, International Journal of Production Research, Vol. 54, No.15, 2016, pp. 4547-4567

[5] L. Horváth, I. J. Rudas: Active Knowledge for the Situation-Driven Control of Product Definition, Acta Polytechnica Hungarica, Vol. 10, No. 2, 2013, pp. 217-234

[6] M. Cantamessa, F. Montagna, P. Neirotti: An Empirical Analysis of the PLM Implementation Effects in the Aerospace Industry, Computers in Industry, Vol. 63, No. 3, 2012, pp. 243-251

[7] A. A. Zaidan, B. B. Zaidan, M. Hussain, A. Haiqi, M. M. Kiah, M. Abdulnabi: Multi-Criteria Analysis for OS-EMR Software Selection Problem: A Comparative Study, Decision Support System, Vol. 78, 2015, pp. $15-27$

[8] M. Hanine, O. Boutkhoum, A. Tikniouine, T. Agouti: Application of an Integrated Multi-Criteria Decision Making AHP-TOPSIS Methodology for ETL Software Selection, SpringerPlus, Vol. 5, No. 1, 2016, p. 263

[9] S. S. Kara, N. Cheikhrouhou: A Multi Criteria Group Decision Making Approach for Collaborative Software Selection Problem, Journal of Intelligent and Fuzzy Systems, Vol. 26, No. 1, 2014, pp. 37-47

[10] B. Efe: An Integrated Fuzzy Multi Criteria Group Decision Making Approach for ERP System Selection, Applied Soft Computing, Vol. 38, 2016, pp. 106-117

[11] H. R. Yazgan, S. Boran, K. Goztepe: An ERP Software Selection Process with Using Artificial Neural Network Based on Analytic Network Process Approach, Expert Systems with Applications, Vol. 36, No. 5, 2009, pp. 9214-9222 
[12] T. Gürbüz, S. E. Alptekin, G. I. Alptekin: A Hybrid MCDM Methodology for ERP Selection Problem with Interacting Criteria, Decision Support Systems, Vol. 54, No. 1, 2012, pp. 206-214

[13] Y. C. Lee, N. H Tang, V. Sugumaran: Open Source CRM Software Selection Using the Analytic Hierarchy Process, Information Systems Management, Vol. 31, No. 1, 2014, pp. 2-20

[14] S. Shukla, P. K. Mishra, R. Jain, H. C. Yadav: An Integrated Decision Making Approach for ERP System Selection Using SWARA and PROMETHEE Method, International Journal of Intelligent Enterprise, Vol. 3, No. 2, 2016, pp. 120-147

[15] S. Rouhani, S. Rouhani: A Fuzzy Superiority and Inferiority Ranking Based Approach for IT Service Management Software Selection, Kybernetes, Vol. 46, No. 4, 2017, pp. 728-746

[16] M. Radojicic, M. Zizovic, Z. Nesic, J. Vesic Vasovic: Modified Approach to PROMETHEE for Multi-Criteria Decision-Making, Maejo International Journal of Science and Technology, Vol. 7, No. 3, 2013, pp. 408-421

[17] Y. Z. Liu, Z. P. Fan, G. X. Gao: An Extended LINMAP Method for MAGDM Under Linguistic Hesitant Fuzzy Environment, Journal of Intelligent and Fuzzy Systems, Vol. 30, No. 5, 2016, pp. 2689-2703

[18] A. Hafezalkotob, A. Hafezalkotob: Fuzzy Entropy-Weighted MULTIMOORA Method for Materials Selection, Journal of Intelligent and Fuzzy Systems, Vol. 31, No. 3, 2016, pp. 1211-1226

[19] X. Yang, Z. J. Wang: Geometric Least Square Models for Deriving-Valued Interval Weights from Interval Fuzzy Preference Relations Based on Multiplicative Transitivity, Mathematical Problems in Engineering, 2015

[20] T. L. Saaty: The Analytic Hierarchy Process, New York, NY: McGrawHill, 1980

[21] Y. M. Wang, K. S. Chin: A Linear Programming Approximation to the Eigenvector Method in the Analytic Hierarchy Process, Information Sciences, Vol. 181, No. 23, 2011, pp. 5240-5248

[22] T. L. Saaty, L. G. Vargas: Comparison of Eigenvalue, Logarithmic Least Squares and Least Squares Methods in Estimating Ratios, Mathematical Modelling, Vol. 5, No. 5, 1984, pp. 309-324

[23] N. Bryson: A Goal Programming Method for Generating Priority Vectors, Journal of the Operational Research Society, Vol. 46, No. 5, 1995, pp. 641648

[24] L. Mikhailov: A Fuzzy Programming Method for Deriving Priorities in the Analytic Hierarchy Process, Journal of the Operational Research Society, Vol. 51, 2000, pp. 341-349 
[25] B. Chandran, B. Golden, E. Wasil: Linear Programming Models for Estimating Weights in the Analytic Hierarchy Process, Computers and Operations Research, Vol. 32, 2005, pp. 2235-2254

[26] X. U. Ye-jun, D. A. Qing-li: Weighted Least-Square Method and Its Improvement for Priority of Incomplete Complementary Judgement Matrix, Systems Engineering and Electronics, Vol. 7, 2008, p. 021

[27] Y. Xu, R. Patnayakuni, H. Wang: Logarithmic Least Squares Method to Priority for Group Decision Making with Incomplete Fuzzy Preference Relations, Applied Mathematical Modelling, Vol. 37, No. 4, 2013, pp. 2139-2152

[28] B. T. Sivrikaya, A. Kaya, M. Dursun, F. Çebi: Fuzzy AHP-Goal Programming Approach for a Supplier Selection Problem, Research in Logistics and Production, Vol. 5, No. 3, 2015, pp. 271-285

[29] J. Barzilai: Deriving Weights from Pairwise Comparison Matrices, Journal of the Operational Research Society, Vol. 48, No. 12, 1997, pp. 1226-1232

[30] C. C. Sun: A Performance Evaluation Model by Integrating Fuzzy AHP and Fuzzy TOPSIS Methods, Expert Systems with Applications, Vol. 37, No. 12, 2010, pp. 7745-7754

[31] S. Nestic: M. Stefanovic, A. Djordjevic, S. Arsovski, D. Tadic: A Model of the Assessment and Optimisation of Production Process Quality Using the Fuzzy Sets and Genetic Algorithm Approach, European Journal of Industrial Engineering, Vol. 9, No. 1, 2015, pp. 77-99

[32] P. J. M. Van Laarhoven, W. Pedrycz: A Fuzzy Extension of Saaty's Priority Theory, Fuzzy Sets and Systems, Vol. 11, No. 1-3, 1983, pp. 229-241

[33] J. J. Buckley: Fuzzy Hierarchical Analysis, Fuzzy Sets and Systems, Vol. 17, No. 3, 1985, pp. 233-247

[34] D. Y. Chang: Applications of the Extent Analysis Method on Fuzzy AHP, European Journal of Operational Research, Vol. 95, No. 3, 1996, pp.649655

[35] R. Xu: Fuzzy Least-Squares Priority Method in the Analytic Hierarchy Process, Fuzzy Sets and Systems, Vol. 112, No. 3, 2000, pp. 395-404

[36] R. Csutora, J. J. Buckley: Fuzzy Hierarchical Analysis: the Lambda-Max Method, Fuzzy Sets and Systems, Vol. 120, No. 2, 2001, pp. 181-195

[37] L. Mikhailov: Deriving Priorities from Fuzzy Pairwise Comparison Judgements, Fuzzy Sets and Systems, Vol. 134, No. 3, 2003, pp. 365-385

[38] Y. M. Wang, J. B. Yang, D. L. Xu: A Two-Stage Logarithmic Goal Programming Method for Generating Weights from Interval Comparison Matrices, Fuzzy Sets and Systems, Vol. 152, No. 3, 2005, pp. 475-498 
[39] Y. M. Wang, T. M. Elhag, Z. Hua: A Modified Fuzzy Logarithmic Least Squares Method for Fuzzy Analytic Hierarchy Process, Fuzzy Sets and Systems, Vol. 157, No. 23, 2006, pp. 3055-3071

[40] J. P. Brans, P. Vincke: A Preference Ranking Organisation Method: (The PROMETHEE Method for Multiple Criteria Decision-Making), Management Science, Vol. 31, No. 6, 1985, pp. 647-656

[41] B. Mareschal, J. P. Brans: Geometrical Representations for MCDA, European Journal of Operational Research, Vol. 34, No. 1, 1988, pp. 69-77

[42] J. P. Brans, B. Mareschal: PROMETHEE V: MCDM Problems with Segmentation Constraints, INFOR: Information Systems and Operational Research, Vol. 30, No. 2, 1992, pp. 85-96

[43] J. P. Brans, and B. Mareschal, The PROMETHEE VI Procedure: How to Differentiate Hard from Soft Multicriteria Problems, Journal of Decision Systems, Vol. 4, No. 3, 1995, pp. 213-223

[44] J. Figueira, Y. De Smet, J. P. Brans: MCDA Methods for Sorting and Clustering Problems: PROMETHEE TRI and PROMETHEE CLUSTER, Université Libre de Bruxelles. Service deMathématiques de la Gestion (Working Paper 2) 2004

[45] M. Goumas, V. Lygerou: An Extension of the PROMETHEE Method for Decision Making in Fuzzy Environment: Ranking of Alternative Energy Exploitation Projects, European Journal of Operational Research, Vol. 123, No. 3, 2000, pp. 606-613

[46] A. Sanga, I. M. Venter: Algorithm for the Evaluation of Free and Open Source Software When the Evaluator is "Uncertain", International Journal of Management Science and Information Technology (IJMSIT) Vol. 17, 2015, pp. 36-55

[47] S. Rouhani, A. Z. Ravasan: A Fuzzy TOPSIS Based Approach for ITSM Software Selection, International Journal of IT/Business Alignment and Governance (IJITBAG), Vol. 5, No. 2, pp. 2014, 1-26

[48] G. Rincon, M. Alvarez, M. Perez, S. Hernandez: A Discrete-Event Simulation and Continuous Software Evaluation on a Systemic Quality Model: An Oil Industry Case, Information and Management, Vol. 42, No. 8, 2005, pp. 1051-1066

[49] Y. Kazancoglu, S. Burmaoglu: ERP Software Selection with MCDM: Application of TODIM Method, International Journal of Business Information Systems, Vol. 13, No. 4, 2013, pp. 435-452

[50] A. Benlian, T. Hess: Comparing the Relative Importance of Evaluation Criteria in Proprietary and Open Source Enterprise Application Software Selection-a Conjoint Study of ERP and Office Systems, Information Systems Journal, Vol. 21, No. 6, 2011, pp. 503-525 
[51] Z. Ayağ, R. G. Özdemir: An Intelligent Approach to ERP Software Selection through Fuzzy ANP, International Journal of Production Research, Vol. 45, No. 10, 2007, pp. 2169-2194

[52] B. S. Sahay, A. K. Gupta: Development of Software Selection Criteria for Supply Chain Solutions, Industrial Management and Data Systems, Vol. 103, No. 2, 2003, pp. 97-110

[53] L. Kaur, D. H. Singh: Software Component Selection Techniques-A Review, International Journal of Computer Science and Information Technologies, Vol. 5, No. 3, 2014, p. 2 